\title{
Silica nanoparticle-mediated, Electric field- triggered sensitivity enhancement strategy for Capillary electrophoretic detection of proteins
}

\author{
Aimin Wang and Weidong Qin* \\ Beijing Normal University, Beijing, China
}

\section{Article Info}

*Corresponding author:
Weidong Qin
Key Laboratory of Theoretical and
Computational Photochemistry
Ministry of Education
College of Chemistry
Beijing Normal University
Beijing 100875, China
Fax: +86-10-58802531
Email: qinwd@bnu.edu.cn

Received: October 27, 2016

Accepted: November 10, 2016

Published: November 14, 2016

Citation: Wang A, Qin W. Silica nanoparticlemediated, Electric field-triggered sensitivity enhancement strategy for Capillary electrophoretic detection of proteins. Madridge J Anal Sci Instrum. 2016; 1(1): 11-15. doi: $10.18689 / \mathrm{mjai}-1000103$

Copyright: $\bigodot^{\circ} 2016$ The Author(s). This work is licensed under a Creative Commons Attribution 4.0 International License, which permits unrestricted use, distribution, and reproduction in any medium, provided the original work is properly cited.

Published by Madridge Publishers

\begin{abstract}
We report in this paper the improved capillary electrophoresis (CE)-UV detection sensitivity of proteins based on silica nanoparticle-mediated, electric field-triggered (SNM-EFT) strategy. During the process, the capillary was first filled with acidic separation buffer, followed by injection of a segment of alkaline treating solution containing silica nanoparticles (SNPs). After the inlet end of the capillary was dipped into the protein solution containing SNPs, a high voltage was applied across the capillary. The SNPs in the protein solution became aggregate, promoting the SNP-protein conjugation, by which transformation of the protein structures took place. During $C E$, the unfolded protein desorbed from SNPs, generating stronger signal than the native one due to the more effective exposure of tryptophanyl residues to the polar buffer. The parameters of the treatment protocols, e.g., $\mathrm{pH}$ of the treating solution, concentration of the SNPs presented, the voltage and duration of the electric field applied, had notable effects on the detection sensitivity. Significant improvement in CE-UV response was obtained by the EFT at $-8 \mathrm{kV} \times 60 \mathrm{~s}$ on the protein standards dissolved in $4 \mathrm{mM}$ sodium tetraborate, $1 \mathrm{mM}$ boric acid and $0.015 \%$ SNPs.
\end{abstract}

Keywords: Capillary electrophoresis; Proteins; Silica nanoparticles; Electric field; sensitivity

Abbreviations: SNPs, silica nanoparticles; LZ, lysozyme; BSA, bovine serum albumin; $H B$, hemoglobin; $P E O$, polyethylene oxide; $C E$, capillary electrophoresis

\section{Introduction}

Nanoparticles (NPs) can conjugate with proteins via hydrophobic patches, hydrogen bonding and columbic interactions owing to the large surface area of NPs $[1,2]$ and to the simultaneous presence of hydrophobic, hydrophilic, cationic, and anionic groups at the surface of protein molecules [3]. The NP-protein conjugation is size-dependent, higher degree conjugation takes place with aggregated NPs [4]. Moreover, such interaction often results in tertiary conformational transformation (unfolding) of the protein [5-8].

Capillary electrophoresis (CE) combines well-known advantages of speedy separation, high efficiency, small amount of sample and solvent consumption, and high automation [9-12]. Due to these unique advantages, it has been extensively employed in proteome research. Not surprisingly, NPs have been hyphenated to CE [13-17] and chip-based electrophoresis system [18-20] for protein separation. For example, a buffer containing surfactant-capped gold nanoparticles (AuNPs) allowed simultaneous separation of acidic and basic proteins in a single run $[13,14]$. By employing lipid-based 
liquid crystalline NPs as pseudostationary phase (PSP), green fluorescent protein (GFP) and its mutants were baseline separated at neutral $\mathrm{pH}$ [17]. Moreover, silica nanoparticles (SNPs)acting as PSPs could also render enhanced resolution for proteins [16]. Liu and co-workers reported TiO2 NP-coated open-tubular capillary electrochromatographic separation of proteins [15], in which conalbumin (ConA) and apo-transferrin (apoTf) of similar molecular weight could be baseline separated.

However, in contrast to the large number of report enhancing the resolution, few reports were dedicated to investigate their applicability in sensitive detection of proteins by $C E$. The main reason might be that both the fluorescence emission and UV absorbance decrease upon adsorption of protein to nanoparticles $[7,21]$. Nonetheless, such NP-protein conjugation might be adopted under some circumstances for sensitive protein detection. Studies revealed that the refolding rates of some proteins, such as lysozyme [22], are very slow after deconjugation. The surrounding environments of the amino acid residues in the detached, unfolding proteins might be different than those in the normal proteins. In this context, the UV-active amino acid residues, i.e., tyrosine, tryptophan and phenylalanine, might have different molar absorptivities which would lead to different detection sensitivities. This strategy can be readily realized in CE techniques due to its quick analysis and ease in tuning the chemical properties of the running buffer to facilitate the deconjugation under the electric field.

The aim of this work is to demonstrate the proof-ofprinciple application of the silica nanoparticle-mediated, electric field-triggered (SNM-EFT) sensitivity enhancement strategy for CE-UV detection of unfolded proteins following the decomposition of the SNP-protein complexes. SNPs were employed as model nanoparticles for investigation. To initialize the SNP-protein complexation, a capillary was first filled with separation buffer followed by injection of a segment of alkaline treating solution containing SNPs. After the inlet end of the capillary was dipped into the protein solution containing SNPs, a high voltage was applied across the capillary. A low conductivity zone formed at the interface between the acidic CE buffer and the alkaline treating solution due to neutralization, whereby the SNPs aggregated, moving to the injection vial and promoting the SNP-protein conjugation. The SNM-EFT parameters, e.g., $\mathrm{pH}$ and the SNPs concentration of the treating solution, the electric voltage and duration of EFT, were investigated. Notable improvement in sensitivity was observed for UV detection of the model proteins, especially for lysozyme, suggesting the potential of the strategy in CE analysis of proteins.

\section{Materials and methods Reagents and solutions Reagents}

Hemoglobin (HB) and lysozyme (LZ) were from Sigma (St. Louis, MO, USA); bovine serum albumin (BSA, section V) was purchased from Amresco (Solon, OH, USA). PEO (polyethylene oxide, Mr 1000 000) was supplied by Alfa Aesar (Ward Hill, MA, USA). The SNPs with average diameter of $20 \mathrm{~nm}$ and purity of $99.9 \%$ were bought from Nanjing Nano High-Tech (Jiangsu, China). All the other chemicals were of analytical grade. Double-distilled water was used to prepare buffers and solutions throughout the experiment.

\section{Solutions}

SNP suspension at $1 \%(\mathrm{w} / \mathrm{v})$ was prepared by gradually adding precisely weighed SNPs to double-distilled water under vigorous stirring. Stock solutions of $100 \mathrm{mM}$ phosphoric acid, $100 \mathrm{mM}$ sodium tetraborate and $100 \mathrm{mM}$ boric acid were employed for preparing buffer solutions of desired concentrations and $\mathrm{pH}$ values. Working solutions of protein standards (mixture of $50 \mathrm{mg} \cdot \mathrm{L}-1$ each) were prepared by mixing the individual stock solutions $(10000 \mathrm{mg} \cdot \mathrm{L}-1$ in doubledistilled water) with appropriate volumes of borate buffer, SNPs suspension and diluting with double-distilled water.

\section{Capillary electrophoresis}

The CE-UV system consisted of a DW-P303-1AC capillary electrophoresis high-voltage power supply (Sanchuan High Tech, China) and a CE-10UV detector (Johnsson Separation Science, Liaoning, China) operated at $210 \mathrm{~nm}$. Signal from the detector was acquired and processed with HW2000 chromatography station (Qianpu, Jiangsu, China). A 50-cm long polyimide-coated fused-silica capillary $(40 \mathrm{~cm}$ in effective length) of $75-\mu \mathrm{m}$ i.d. and $375-\mu \mathrm{m}$ o.d. (Yongnian Photoconduction Fibre, Hebei, China) was used for CE. The fresh capillary was consecutively rinsed for 30 min with $1 \mathrm{M}$ $\mathrm{NaOH}, 10$ min with double-distilled water and 5 min with separation buffer. Each electrolyte solution was filtered through a $0.22-\mu \mathrm{m}$ membrane filter (Jiuding High Tech, Beijing, China). Samples were hydrodynamically injected into the capillary by raising the inlet reservoir $20.0 \mathrm{~cm}$ for $30 \mathrm{~s}$. Electrophoretic separations were carried out at a voltage of $11 \mathrm{kV}$ under ambient temperature.

\section{SNM-EFT procedure}

The capillary was first rinsed for 2 min with the separation buffer, followed by hydrodynamic injection of a segment of treating solution by siphon (the optimum parameters were 20 $\mathrm{cm}^{\prime} 40 \mathrm{~s}$ ). After that, the inlet was immersed into the sample vial containing the protein standard solution and the outlet was immersed into the separation buffer. A negative voltage was then applied between the sample and the outlet vials for a desired duration. The capillary was flushed with running buffer for 2 min after the procedure, and the treated protein solution was vigorously shaken before injection.

\section{Results and discussion}

\section{Optimization of CE conditions}

Background electrolyte (BGE) of $20 \mathrm{mM}$ phosphoric acid $(\mathrm{pH} 1.89)$ was employed to suppress the deprotonation of silanol groups of the capillary inner wall and, therefore, to suppress the wall-adsorption of the positively charged proteins. In order to further improve the separation 
performances, PEO was added to the buffer, and its concentration was optimized. Improved peak intensities were observed in the presence of $0.05 \%$ SNPs (Figure 1B vs. $1 \mathrm{~A}$ ). The buffer containing $0.2 \%$ PEO offered the highest resolutions for the proteins (Figure 1C) although the overall sensitivity of the three proteins was slightly lower than that of Figure $1 \mathrm{~B}$. Addition of PEO to the buffer increases the buffer viscosity, resulting in reduced injection volume and consequently the decreased peak heights of the analytes. Taking into account the parameters of resolution and sensitivity, we chose BGE consisting $20 \mathrm{mM}$ phosphoric acid and $0.2 \%$ PEO for the further experiments.

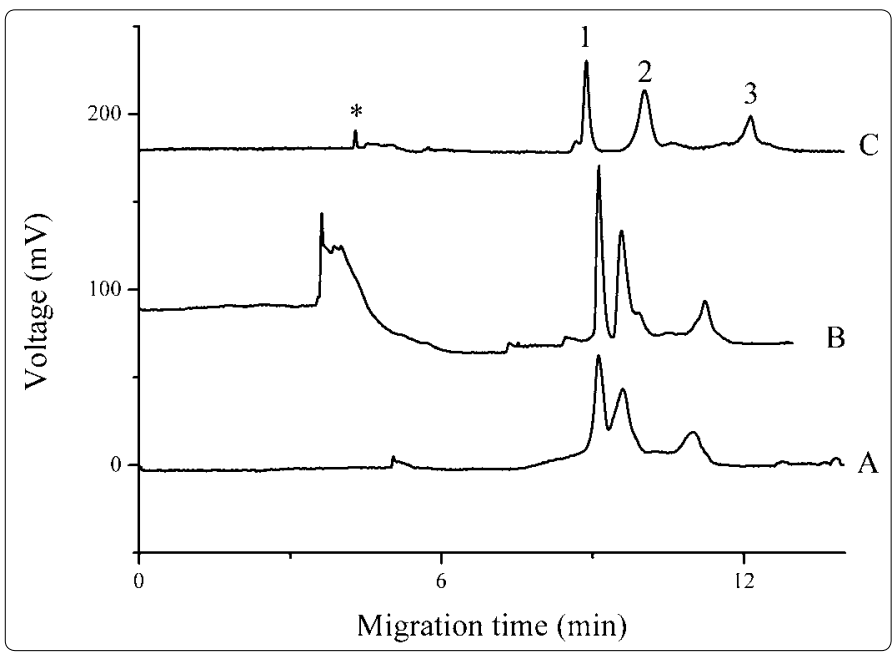

Figure 1. Influence of buffer additives Separations were carried out with BGE of $20 \mathrm{mM}$ phosphoric acid (A), which was added to $0.05 \%$ SNPs $(B)$ or $0.2 \%$ PEO $(C)$. Proteins were dissolved to concentrations of $50 \mathrm{mg} \cdot \mathrm{L}-1$ each in treating solution. Electrophoresis was conducted at $11 \mathrm{kV}$ and UV detection was performed at $210 \mathrm{~nm}$.

Peak identities: $1, \mathrm{LZ} ; 2, \mathrm{BSA} ; 3, \mathrm{HB} ;{ }^{*}$, systemic peak. Electropherograms were offset for clarity.

\section{Preliminary experiments on SNM-EFT}

Experiments were carried out to explore the influence of SNPs and electric field on the detection sensitivity. Two kinds of treating solutions were employed, i.e., $4 \mathrm{mM}$ sodium tetraborate and $1 \mathrm{mM}$ boric acid at $\mathrm{pH}=9.11$ with and without $0.015 \%$ SNPs, they are denoted treating solutions A and B, respectively. Our preliminary experiments suggested that application of positive high voltage did not change the detection sensitivity of the proteins (Figure $1 \mathrm{~S}$ of the Supporting Information); so, a negative voltage was employed. We initially employed same treating solutions for injecting into the capillary and for dissolving the protein standards. Compared to treating solution A (Figure 2A, without EFT), using treating solution $B$ did not result in higher solution; on the contrary, lower peak heights (Fig, 2B, without EFT) were observed, probably due to the higher solution viscosity in the presence of $0.015 \%$ SNPs. With EFT, utilizing treating solution A (Figure 2C) did not bring about noticeable changes in detection sensitivity as compared with Figure 2A. However, when EFT was applied to treating solution $\mathrm{B}$, remarkable improvement of the peak heights was obtained, especially for lysozyme. The results suggest the potential of SNM-EFT strategy in sensitive detection of proteins.

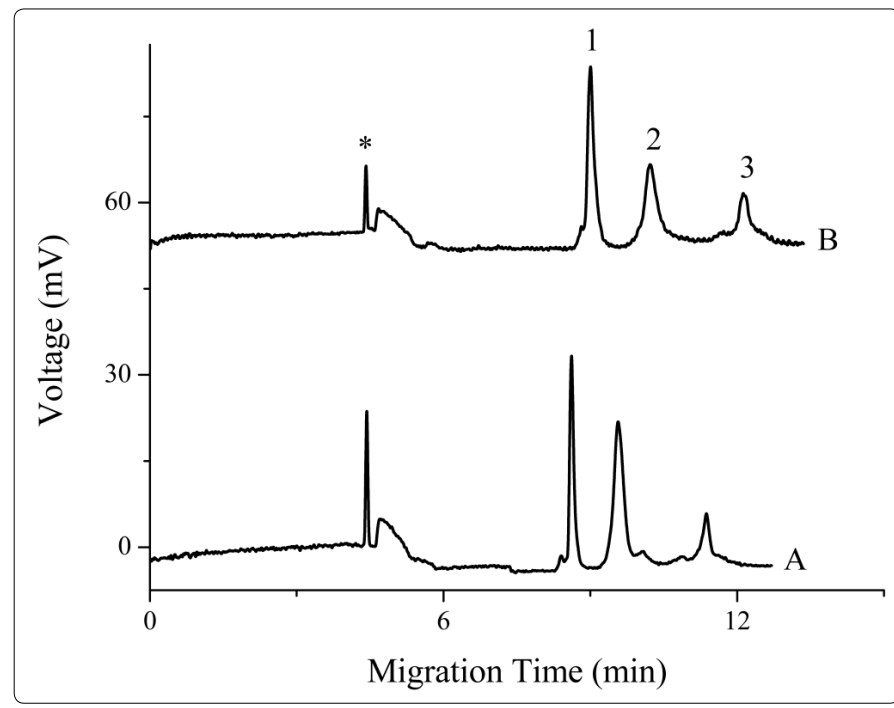

Figure 1S. Effect of positive high voltage on detection sensitivity. Sample treatment techniques: Proteins dissolved in $4 \mathrm{mM}$ sodium tetraborate, $1 \mathrm{mM}$ boric acid and $0.015 \%$ SNPs; the solution was treated for $60 \mathrm{~s}$ at a voltage of (A) $0 \mathrm{kV} ;(B)+8 \mathrm{kV}$.

For better understanding the mechanisms, the SNM-EFT experiments were conducted using different treating solutions for pre-injection and for dissolving protein standards. With pre-injection of treating solution $A$, the detection sensitivities of the proteins (Figure $2 \mathrm{E}$ ) were similar to those in Figure $2 \mathrm{~B}$. Likewise, peak heights of the proteins close to Figure $2 \mathrm{~A}$ were observed with pre-injection of treating solution $B$.

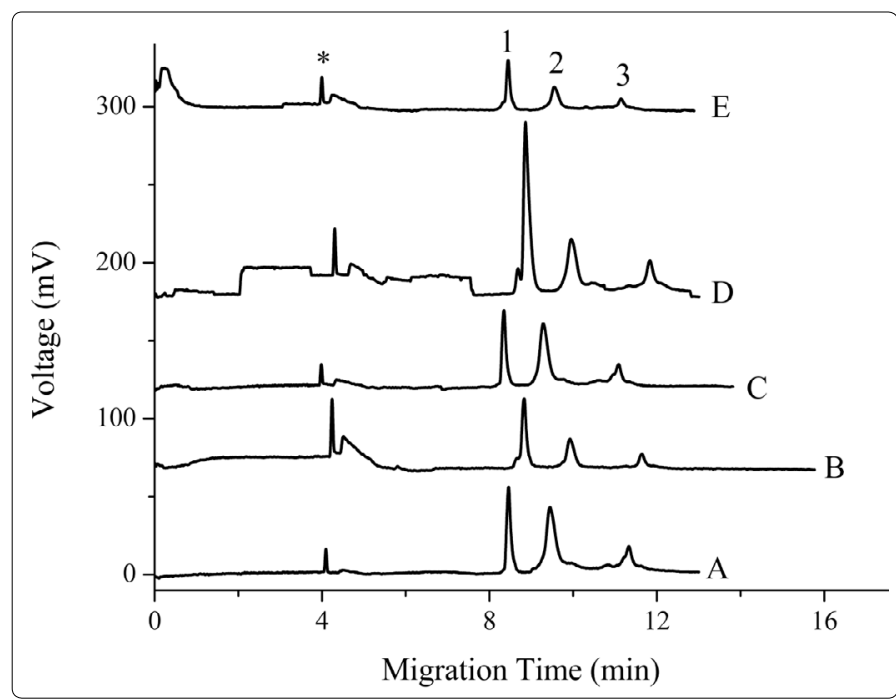

Figure 2. Effect of sample treatment techniques on detection sensitivity. Separation buffer: $20 \mathrm{mM}$ phosphoric acid and $0.2 \%$ PEO. Peak identities: 1, LZ; 2, BSA; 3, HB; *, systemic peak. Preparation and treatment of the standards: (A) Proteins dissolved in treating solution $A$, without EFT; $(B)$ proteins dissolved in treating solution $B$, without $\mathrm{EFT}$; (C) proteins dissolved in treating solution A; EFT: $-8 \mathrm{kV} \times 60 \mathrm{~s}$; (D) proteins dissolved in treating solution $B, E F T:-8 \mathrm{kV} \times 60 \mathrm{~s}$. In $(A)-(D)$, the plug of treating solution in each trace, introduced by $20 \mathrm{~cm}$ ' $40 \mathrm{~s}$, was the same with that used in preparing the corresponding protein standards. (E) proteins were dissolved in treating solution $B$; treating solution A was injected into the capillary $(20 \mathrm{~cm}$ ' $40 \mathrm{~s})$; EFT: $8 \mathrm{kV} \times$

$60 \mathrm{~s}$. Other conditions were the same as those in Figure 1.

During EFT process, a $\mathrm{pH}$ junction was formed at the boundary between the alkaline treating solution and the acidic separation buffer. The hydrogen ion $(\mathrm{H}+)$ from the $B G E$ 
intruded into the treating solution plug under electric field and reacted with $\mathrm{OH}$ - and $\mathrm{B}(\mathrm{OH}) 4$-, forming a low-conductivity zone where SNPs began to aggregate [23,24]. These aggregates were carried into the cathodic sample vial by EOF, broadening the primary particle size distribution (PPSD) and consequently accelerating the aggregating rate of the SNPs [25], promoting the SNP-protein conjugation.

\section{Effect of SNP concentration and pH}

Figure 3 depicts that under an EFT treatment of $-8 \mathrm{kV} \times$ $60 \mathrm{~s}$, the peak height of LZ increases gradually with the increasing concentration of SNPs until $0.015 \%$, from which the peak height kept at a relatively stable level. However, the peak height of $\mathrm{HB}$ did not show significant improvement in the presence of SNPs; moreover, addition of SNPs even caused slightly decreased response of BSA. We suggest that presence of SNPs improves the viscosity of the sample solution, resulting in low injection volume and, hence, low detector response. Therefore, the concentration of SNPs was kept at $0.015 \%$.

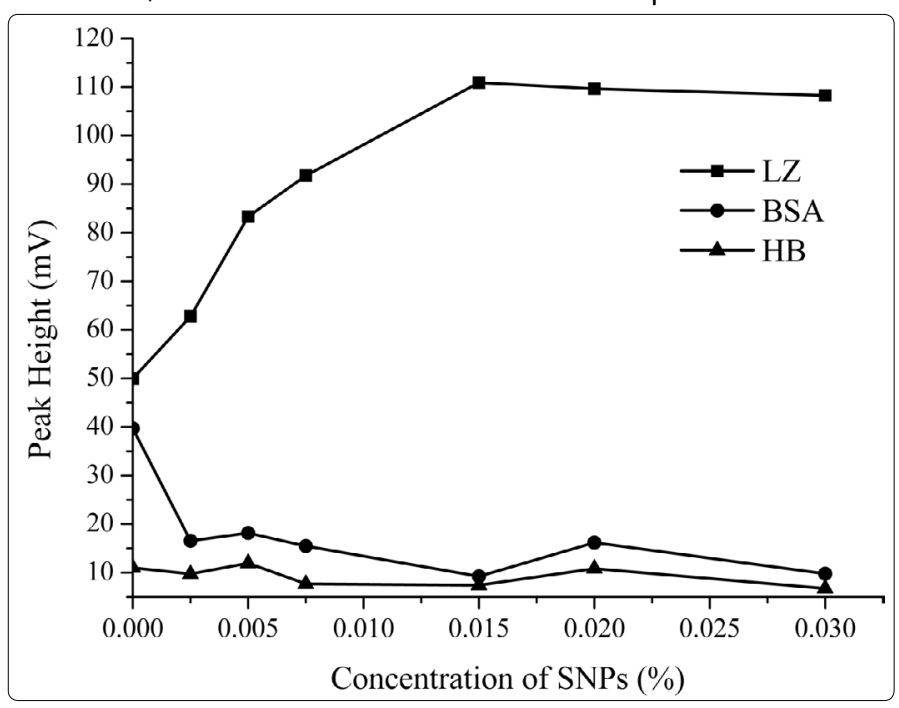

Figure 3. Dependence of peak heights on the concentration of SNPs presented in the treating solution. The protein concentrations

were $50 \mathrm{mg} \cdot \mathrm{L}-1$ each. The treating solution in the experiment contained $4 \mathrm{mM}$ sodium tetraborate, $1 \mathrm{mM}$ boric acid and varying concentrations of SNPs from 0 to $0.03 \%$. The other conditions were the same as those in Figure 2

To study the influence of treating solution $\mathrm{pH}$, proteins were dissolved in different treating solutions of $4 \mathrm{mM} \mathrm{H} 3 \mathrm{PO} 4$ $(\mathrm{pH}=2.11), 10 \mathrm{mM} \mathrm{NaH} 2 \mathrm{PO} 4(\mathrm{pH}=4.27)$ and $4 \mathrm{mM}$ sodium tetraborate $(\mathrm{pH}=9.11)$. All solutions were added with SNPs to $0.015 \%$. Application of electric field did not lead to enhanced detection sensitivity with proteins dissolved in acidic treating solution; but it did in alkaline solutions.

Adsorption of LZ onto SNPs was influenced by the nanoparticle size and solution $\mathrm{pH}$. Multilayer adsorption and greater conformational change occurred with proteins attached on SNPs of larger size [4]. High solution $\mathrm{pH}$ promotes these progresses [4].

\section{Effect of electric voltage and treating duration}

Significant enhancement in the response of $L Z$ was observed at negative voltages ranged from -8 to $-10 \mathrm{kV}$ (Figure 4). LZ is positively charged in buffer of $\mathrm{pH} 9.11$ because its isoelectric point is ca 11. The results reveal that the complementary electrostatic interaction facilitates the adsorption of LZ to SNPs $[4,22]$. It is interesting to find that the negatively charged $\mathrm{BSA}$ and $\mathrm{HB}$, which should be electrostatically repulsive to the SNPs, also indicate considerable enhancement in detection sensitivity. The hydrophobic interaction might be responsible for the adsorption of proteins to SNPs under this circumstance [7]. Moreover, it was reported [26] that BSA and HB possess low internal stability; they are "soft" and are prone to adsorb on all surfaces irrespective of electrostatic interactions.

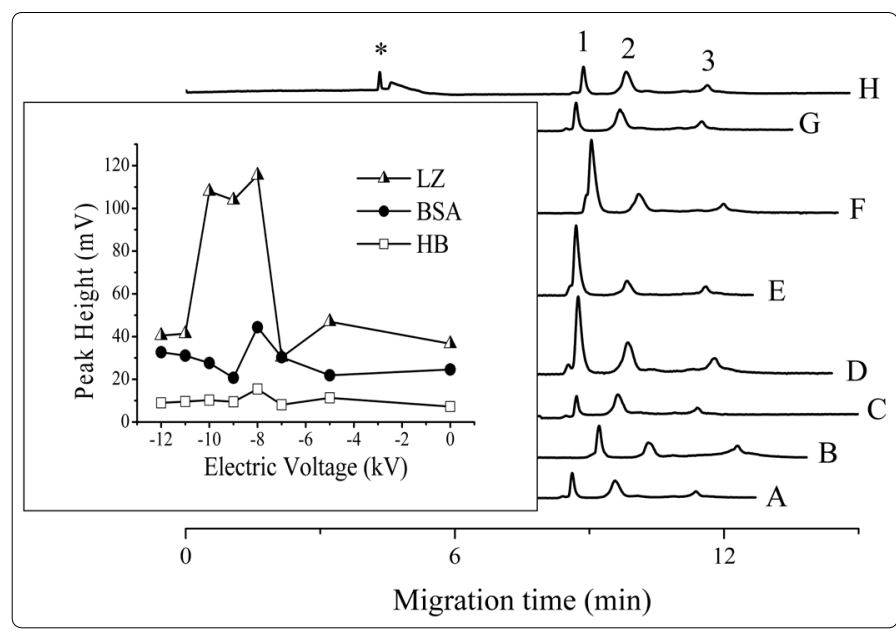

Figure 4. Effect of electric voltage on detection sensitivity. The sample solutions underwent EFT treatments for $60 \mathrm{~s}$ at the following voltages: (A) 0 kV; (B) -5 kV; (C) -7 kV; (D) $-8 k V$; (E) -9 kV; (F) -10 $k V_{i}(G)-11 k V_{i}(H)-12 k V$. Figures in the inset: dependence of peak heights of proteins on the electric voltages. The other conditions were the same as those in Figure 2.

The treating time is another important factor influencing the sensitivity; the peak height of LZ increased with the duration first to a maximum at $60 \mathrm{~s}$, then decreased with further extended duration.

In the SNM-EFT strategy, high voltage generates high EOF intensity and large amount of SNP aggregates, favoring high sensitivity. Nevertheless, high migration velocities of the ions in the capillary disturb the $\mathrm{pH}$ junction and, even worse, under some circumstances, for example, the long EFT time, the acidic buffer may enter the sample vial. The former does not favor formation of aggregated SNPs, whereas the latter will weaken the protein-SNP interaction $[4,27]$.

\section{Conclusions}

We report the proof-of-principle application of SNM-EFT strategy for sensitive CE-UV detection of proteins. Influences of SNP concentration and $\mathrm{pH}$ of the treating solution, the treating electric voltage and duration were investigated. The SNP aggregates generated during the EFT promoted the aggregation of the SNPs in the standard solution and, as a result, favored the SNP-protein interaction. The unfolded protein desorbed from the SNPs during CE could produce enhanced UV-absorbance signal. Due to the great variety of nanoparticles and the wide $\mathrm{pH}$ range of the $\mathrm{CE}$ buffers employed in proteome research, we expect the method opens up new opportunities for sensitive detection of more proteins. 


\section{Acknowledgements}

This work was supported by the National Natural Science Foundation of China (21575017) and the Fundamental Research Funds for the Central Universities.

Conflicts of Interest: The authors have declared no conflict of interest.

\section{References}

1. Assfalga M, Ragonab L, Paganob K, D'Onofrioa M, Zanzonia S, Tomasellib $\mathrm{S}$, et al. The study of transient protein-nanoparticle interactions by solution NMR spectroscopy. Bba-Proteins Proteom. 2016;1864(1):10214. http://dx.doi.org/10.1016/j.bbapap.2015.04.024

2. Kelly PM, Aberg C, Polo E, O'Connell A, Cookman J, Fallon J, et al. Mapping protein binding sites on the biomolecular corona of nanoparticles. Nature Nanotechnology. 2015;10(5):472-479. doi: 10.1038/nnano.2015.47

3. Manabe T. Capillary electrophoresis of proteins for proteomic studies. Electrophoresis. 1999;20(15-16):3116-21. doi: 10.1002/(SICI)15222683(19991001)20:15/16<3116::AID-ELPS3116>3.0.CO;2-0

4. Vertegel AA, Siegel RW, Dordick JS. Silica nanoparticle size influences the structure and enzymatic activity of adsorbed lysozyme. Langmuir. 2004;20(16):6800-6807. doi: 10.1021/la0497200

5. Czeslik C, Winter R. Effect of temperature on the conformation of lysozyme adsorbed to silica particles. Phys Chem Chem Phys. 2001;3(2):235-9. doi: 10.1039/B005900P

6. Brewer SH, Glomm WR, Johnson MC, Knag MK, Franzen S. Probing BSA binding to citrate-coated gold nanoparticles and surfaces. Langmuir. 2005;21(20):9303-7. doi: 10.1021/la050588t

7. Shang L, Wang YZ, Jiang JG, Dong SJ. pH-dependent protein conformational changes in albumin : gold nanoparticle bioconjugates: A spectroscopic study. Langmuir. 2007;23(5):2714-21. doi: 10.1021/la062064e

8. You CC, De M, Han G, Rotello VM. Tunable inhibition and denaturation of alpha-chymotrypsin with amino acid-functionalized gold nanoparticles. J Am Chem Soc. 2005;127(37):12873-81. doi: 10.1021/ja0512881

9. Heemskerk AAM, Deelder AM, Mayboroda OA. CE-ESI-MS for bottomup proteomics: Advances in separation, interfacing and applications. Mass Spectrom Rev. 2016;35(2):259-71. doi: 10.1002/mas.21432

10. Chen J, Ni Y, Liu CC, Yamaguchi Y, Chen Q, Sekine $S$ et al. Rapid identification and quantitation for oral bacteria based on short-end capillary electrophoresis. Talanta. 2016;160:425-30. doi: 10.1016/j. talanta.2016.07.049

11. Mendes TD, Porto BLS, Bell MJV, Perrone ÍT, de Oliveira MA. Capillary zone electrophoresis for fatty acids with chemometrics for the determination of milk adulteration by whey addition. Food Chem. 2016;213:647-53. doi: 10.1016/j.foodchem.2016.07.035

12. Riley KR, Liu S, Yu G, Libby K, Cubicciotti R, Colyer CL. Using capillary electrophoresis to characterize polymeric particles. J Chromatogr A. 2016;1463:169-75. doi: 10.1016/j.chroma.2016.08.017

13. Yu CJ, Su CL, Tseng WL. Separation of acidic and basic proteins by nanoparticle-filled capillary electrophoresis. Anal Chem. 2006;78(23):800410. doi: $10.1021 /$ ac061059c
14. Lin $\mathrm{CY}$, Liu CH, Chang HC, Tseng WL. Enrichment and separation of acidic and basic proteins using the centrifugal ultrafiltration followed by nanoparticle-filled capillary electrophoresis. Electrophoresis. 2008;29(14):3024-31. doi: 10.1002/elps.200700879

15. Hsieh YL, Chen TH, Liu CY. Capillary electrochromatographic separation of proteins on a column coated with titanium dioxide nanoparticles. Electrophoresis. 2006;27(21):4288-94. doi: 10.1002/elps.200500897

16. Qin WD. Silica nanoparticles as pseudostationary phase for protein separation. Electrophoresis. 2007;28(17):3017-23. doi: 10.1002/elps.200600476

17. Nilsson C, Becker K, Harwigsson I, Bülow L, Birnbaum S, Nilsson S. Hydrophobic Interaction Capillary Electrochromatography of Protein Mutants. Use of Lipid-Based Liquid Crystalline Nanoparticles as Pseudostationary Phase. Anal Chem. 2009;81(1):315-21. doi: 10.1021/ ac8020533

18. Dou YH, Bao N, Xu JJ, Meng F, Chen HY. Separation of proteins on surfacemodified poly(dimethylsiloxane) microfluidic devices. Electrophoresis. 2004;25(17):3024-31. doi: 10.1002/elps.200405986

19. Wang AJ, Xu JJ, Chen HY. Proteins modification of poly(dimethylsiloxane) microfluidic channels for the enhanced microchip electrophoresis. J Chromatogr A. 2006;1107(1-2):257-64. http://dx.doi.org/10.1016/j. chroma.2005.12.040

20. Kim HR, Andrieux K, Delomenie $C$, et al. Analysis of plasma protein adsorption onto PEGylated nanoparticles by complementary methods: 2-DE, CE and protein Lab-on-chip((R)) system. Electrophoresis. 2007;28(13):2252-61.

21. Sun $C X$, Wu $X$, Ding HH, Zhao L, Wang F, Yang J. The Fluorescence Enhancement of the Protein Adsorbed on the Surface of Ag Nanoparticle. J Fluoresc. 2009;19(1):111-7. doi: 10.1007/s10895-008-0392-4

22. Wu XY, Narsimhan G. Effect of surface concentration on secondary and tertiary conformational changes of lysozyme adsorbed on silica nanoparticles. Bba-Proteins Proteom. 2008;1784(11):1694-701. doi: 10.1016/j.bbapap.2008.06.008

23. Prasher R, Phelan PE, Bhattacharya P. Effect of aggregation kinetics on the thermal conductivity of nanoscale colloidal solutions (nanofluid). Nano Lett. 2006;6(7):1529-34. doi: 10.1021/nl060992s

24. Fedeyko JM, Vlachos DG, Lobo RF. Formation and structure of selfassembled silica nanoparticles in basic solutions of organic and inorganic cations. Langmuir. 2005;21(11):5197-206. doi: 10.1021/la0468390

25. Peng ZB, Doroodchi E, Evans GM. Influence of primary particle size distribution on nanoparticles aggregation and suspension yield stress: $A$ theoretical study. Powder Technol. 2012;223:3-11. http://dx.doi. org/10.1016/j.powtec.2011.11.001

26. Lucy CA, MacDonald AM, Gulcev MD. Non-covalent capillary coatings for protein separations in capillary electrophoresis. J Chromatogr A. 2008;1184(1-2):81-105. http://dx.doi.org/10.1016/j.chroma.2007.10.114

27. Haynes CA, Sliwinsky E, Norde W. Structural and electrostatic properties of globular proteins at a polystyrene-water interface. $J$ Colloid Interface Sci. 1994;164(2):394-9. doi: 10.1006/jcis.1994.1182 